\title{
Suppression of Human Prostate Cancer Cell Growth by $\beta$-Lapachone via Down-regulation of pRB Phosphorylation and Induction of Cdk Inhibitor p21 ${ }^{\text {WAFI/CIPI }}$
}

\author{
Yung Hyun Choi*, Ho Sung Kang ${ }^{\dagger}$ and Mi-Ae Yoo ${ }^{\dagger}$ \\ Department of Biochemistry, College of Oriental Medicine, Dong-Eui University and \\ Research Center for Oriental Medicine, Pusan 614-052, Korea \\ 'Department of Molecular Biology, College of Natural Sciences, Pusan National University, Pusan 609-735, Korea
}

Received 31 October 2002, Accepted 22 November 2002

\begin{abstract}
The product of a tree (Tabebuia avellanedae) from South America, $\beta$-lapachone, is known to exhibit various pharmacological properties, the mechanisms of which are poorly understood. The aim of the present study was to further elucidate the possible mechanisms by which $\beta$ lapachone exerts its anti-proliferative action in cultured human prostate cancer cells. We observed that the proliferation-inhibitory effect of $\boldsymbol{\beta}$-lapachone was due to the induction of apoptosis, which was confirmed by observing the morphological changes and cleavage of the poly(ADP-ribose) polymerase protein. A DNA flow cytometric analysis also revealed that $\beta$-lapachone arrested the cell cycle progression at the G1 phase. The effects were associated with the down-regulation of the phosphorylation of the retinoblastoma protein (pRB) as well as the enhanced binding of pRB and the transcription factor E2F-1. Also, $\beta$-lapachone suppressed the cyclindependent kinases (Cdks) and cyclin E-associated kinase activity without changing their expressions. Furthermore, this compound induced the levels of the Cdk inhibitor p21 ${ }^{\text {WAFI/CIPI }}$ expression in a p53-independent manner, and the p21 proteins that were induced by $\beta$-lapachone were associated with Cdk2. $\beta$-lapachone also activated the reporter construct of a p21 promoter. Overall, our results demonstrate a combined mechanism that involves the inhibition of pRB phosphorylation and induction of p21 as targets for $\beta$-lapachone. This may explain some of its anticancer effects.
\end{abstract}

Keywords: Apoptosis, $\beta$-Lapachone, G1 arrest, pRB, p21

\footnotetext{
*To whom correspondence should be addressed.

Tel: 82-51-850-7413; Fax: 82-51-853-4036

E-mail: choiyh@dongeui.ac.kr
}

\section{Introduction}

$\beta$-Lapachone (3,4-dihydro-2,2-dimenthyl-2H-napthol[1,2-b] pyran-5,6-dione) is a naturally occurring plant quinone that is obtained from the bark of the lapacho tree (Tabebuia avellanedae), which is native to South America (SchaffnerSabba et al., 1984). This compound inhibits reverse transcriptase and DNA polymerase- $\alpha$, and blocks DNA repair that sensitizes tumor cells to DNA-damaging agents (Boorstein and Pardee, 1984; Schaffner-Sabba et al., 1984; Boothman et al., 1989). Several studies suggested that $\beta$-lapachone could directly target DNA topoisomerases and inhibit their activity, which would result in cytotoxicity (Li et al., 1993; Frydman et al., 1997; Li et al., 2000; Pardee et al., 2002). However, its inhibitory mode is distinct from that of other typical topoisomerase inhibitors, such as camptothecin and its related compounds (Li et al., 1993). $\beta$-lapachone exhibits other pharmacological actions. These include anti-bacterial, antifungal, and anti-trypanocidal actions (Lopes et al., 1978; Goijman and Stoppani, 1985; Guiraud et al., 1994), which are linked to the formation of reactive oxygen species (Cruz et al., 1978; Docampo et al., 1979). In addition, it has been known that $\beta$-lapachone induces apoptotic cell death in human leukemia and the prostate cancer cell line in a p53-independent pathway, which implicated its potential clinical utility against both cancers (Li et al., 1995; Planchon et al., 1995). Vanni et al. (1998) reported that the cytotoxic effects of $\beta$-lapachone are related to the reduced enzymatic activity of poly(ADP-ribose) polymerase (PARP). This suggests that the inhibition of PARP plays a central role in the complex biological effects that are induced by $\beta$-lapachone. Recently, the inhibition of the nuclear transcription factor- $\mathrm{\kappa B}$ and activator protein-1 activity by $\beta$ lapachone explained some of its pharmacological effects as novel targets for $\beta$-lapachone (Manna et al., 1999). However, the molecular mechanisms of its anti-proliferative action on cell growth are not completely known. 
The present study was carried out to characterize the probable mechanisms that are involved in the $\beta$-lapachonemediated growth inhibitory effect in human prostate carcinoma cells. We demonstrated that $\beta$-lapachone induced cell cycle arrest at the G1 phase, and apoptosis through a combined mechanism that involved the down-regulation of the phosphorylation of $\mathrm{pRB}$ and the induction of the Cdk inhibitor $\mathrm{p} 21$.

\section{Materials and Methods}

Cell culture and $\beta$-lapachone The human prostate carcinoma PC-3 cells were cultured in a RPMI 1640 medium (Gibco BRL, Gaithersburg, USA), as previously described (Choi et al., 1997). $\beta$ Lapachone was purchased from Biomol (Plymouth Meeting, USA) and dissolved in ice-cold absolute alcohol as a stock solution at a 10 $\mathrm{mM}$ concentration. It was stored in aliquots at $-20^{\circ} \mathrm{C}$.

Growth study and morphology For the growth inhibition analysis, the cells were cultured in the absence or presence of $\beta$ lapachone for $6 \mathrm{~h}$. After an additional $24 \mathrm{~h}$ of culture in a normal medium, the cells were trypsinized, washed with phosphatebuffered saline (PBS), and the viable cells were scored with a hemacytometer through exclusion of trypan blue. For the morphological study, the cells were grown on a coverslip and treated with $\beta$-lapachone for $6 \mathrm{~h}$. They were Wright-stained (Fisher Scientific, Pittsburgh, USA) after $24 \mathrm{~h}$, as recommended by the manufacturer.

Cell cycle analysis The cells were trypsinized, washed with PBS, and fixed in $75 \%$ ethanol at $4^{\circ} \mathrm{C}$ for $30 \mathrm{~min}$. Prior to the analyses, the cells were again washed with PBS, suspended in a cold propidium iodide (PI, Sigma Chemical Co., St. Louis, USA) solution (Choi et al., 2000; Shim et al., 2002), and incubated at room temperature in the dark for $30 \mathrm{~min}$. Flow cytometry analyses were performed on a FACScan flow cytometry system (Becton Dickinson, San Jose, USA).

Nuclear staining with DAPI The cells were washed with PBS and fixed with $3.7 \%$ paraformaldehyde in PBS for $10 \mathrm{~min}$ at room temperature. The fixed cells were washed with PBS, and stained with a 4,6-diamidino-2-phenylindole (DAPI, Sigma, St. Louis, USA) solution for $10 \mathrm{~min}$ at room temperature. The cells were washed two more times with PBS and analyzed via a fluorescence microscope.

Immunoprecipitation and Western blot analysis The total cell lysates were lysed in an extraction buffer as previously described (Choi et al., 1997). For immunoprecipitation, the cell extracts were incubated with an immunoprecipitating antibody or normal rabbit serum in an extraction buffer for $1 \mathrm{~h}$ at $4^{\circ} \mathrm{C}$. The immuno-complex was collected on protein A-Sepharose beads (Sigma) and separated by a SDS-polyacrylamide gel electrophoresis and transferred to nitrocellulose membranes (Schleicher \& Schuell, Keene, USA). A Western blot analysis was performed, as described (Choi et al., 1997), using the enhanced-chemiluminescence (ECL) detection system (Amersham Corp., Arlington Height, USA). The polyclonal antibodies to cyclin E, Cdk2, Cdk4 and monoclonal anti-E2F-1, and monoclonal antibodies to pRB and p21 were obtained from Santa Cruz Biotechnology Inc. (Santa Cruz, USA) and Upstate Biotechnology (Lake Placid, USA), respectively. The monoclonal anti-PARP antibody was purchased from Calbiochem (Cambridge, USA). The peroxidase-labeled secondary antibodies were purchased from Amersham.

In vitro immuno-complex kinase assay Whole cell lysates were incubated with a primary antibody, precipitated, and resuspended in a kinase assay mixture buffer (Choi et al., 2000; Kim et al., 2001) that contained $\left[\gamma^{32} \mathrm{P}\right]$ ATP (ICN, Irvine, USA) and histone H1 (Sigma, St. Louis, USA) as a substrate. After incubation at $37^{\circ} \mathrm{C}$ for $30 \mathrm{~min}$, the reaction was stopped by the addition of the same amount of $2 \times$ SDS sample buffer. After boiling and spinning, the samples were separated on $10 \%$ SDS-polyacrylamide gels, dried, and bands were detected by autoradiography.

p21 promoter-luciferase construct and transfection assay The cells were transiently co-transfected with the full-length 2.4-kb human p21 promoter-luciferase reporter construct (Choi et al., 2000 ) and the $\beta$-galactosidase reporter vector $\mathrm{pCMB} \beta$ (Promega, Madison, USA) using the LipofectAMINE transfection reagent (Gibco BRL), according to the manufacturers recommendations. Following transfection, the cells were incubated for $12 \mathrm{~h}$, the medium was exchanged, and the cells were incubated in the presence or absence of $\beta$-lapachone. The cells were then lysed, and the luciferase activity in the lysates was assayed using a Dynatech ML1000 luminometer (Dynatech Laboratories, Chantilly, USA). The luciferase activity was normalized to $\beta$-galactosidase activity, which was assayed using the $\beta$-galactosidase enzyme assay system (Promega, Madison, USA).

\section{Results}

Growth inhibition by $\boldsymbol{\beta}$-lapachone To evaluate the effect of $\beta$-lapachone on cell proliferation, we initially determined the effects of $\beta$-lapachone on the growth of human prostate carcinoma PC-3 cells. As shown in Fig. 1A, $\beta$-lapachone had a strong inhibitory effect on cell proliferation in a concentration-dependent manner (about a 55\% decrease from the baseline in the presence of $3 \mu \mathrm{M} \beta$-lapachone). Analyses of the cell cycle distribution of cells after exposure to $\beta$ lapachone showed that these cells had a marked accumulation in the percentage of cells in the G1 phase of the cell cycle (Fig. 1B). This was accompanied by a significant decrease in their $\mathrm{G} 2 / \mathrm{M}$ phase when compared with the untreated control cells, which suggests that the growth inhibitory effect of $\beta$ lapachone was the result of a block during this G1 phase. Also, these cells did not enter the $\mathrm{S}$ phase.

Morphological changes and apoptotic cell death induced by $\boldsymbol{\beta}$-lapachone An analysis by light microscopy showed that the $\beta$-lapachone-treated cells showed a distinct morphological change. The $\beta$-lapachone-treated cells were 

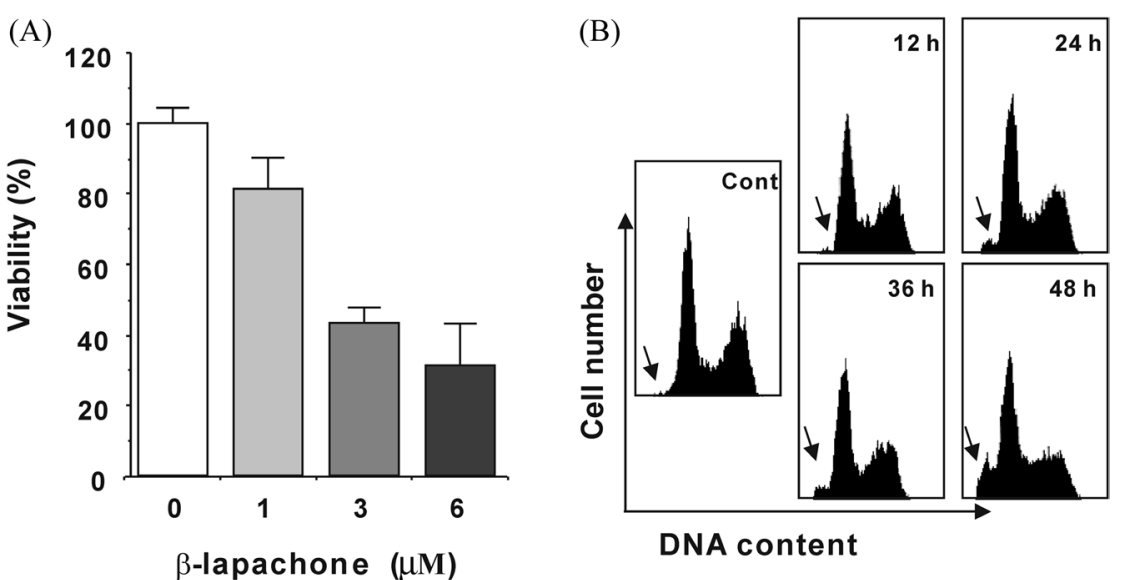

Fig. 1. Growth inhibition and cell cycle arrest by $\beta$-lapachone in PC-3 cells. (A) The cells were plated at $0.5 \times 10^{4}$ cells per 100 -mm plate and incubated for $24 \mathrm{~h}$. The cells were treated with $\beta$-lapachone at $1 \mu \mathrm{M}, 3 \mu \mathrm{M}$, and $6 \mu \mathrm{M}$ concentrations for $6 \mathrm{~h}$, and then the media were changed. After a $24 \mathrm{~h}$ incubation in a normal medium, the cell number was determined by hemacytometer counts of the trypan blue-excluding cells. Each bar represents the mean number of triplicate determinations. Values from each treatment were expressed as a percent relative to the control (100\%). Bars represent the mean $+/$ - SD. (B) Exponentially-growing cells were treated at 0 time with $2 \mu \mathrm{M} \beta$-lapachone. A flow cytometric cell cycle analysis was performed, comparing the untreated controls with the cells that were treated with $\beta$-lapachone for the indicated time. Arrows mean the portions of apoptotic cells, sub-diploid cells.

(A)

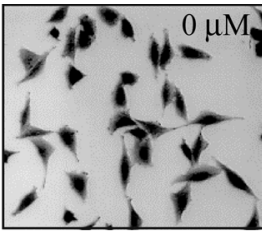

(B)

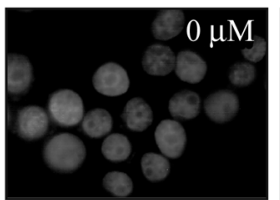

(C)
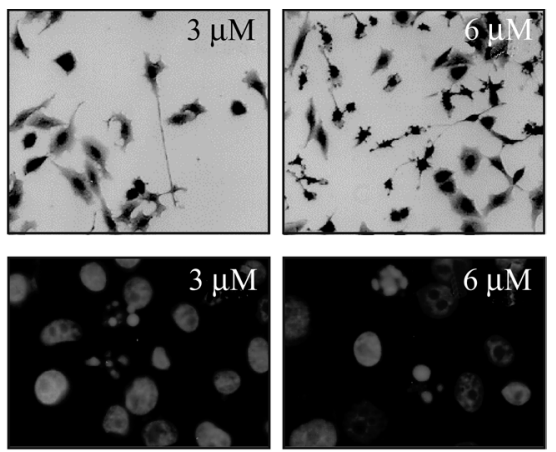

$\beta$-lapachone

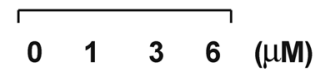

PARP

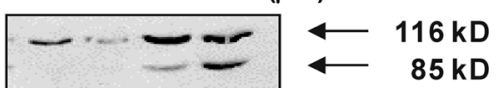

Fig. 2. $\beta$-lapachone-induced morphological changes and apoptosis in PC-3 cells. (A) The cells were incubated with $3 \mu \mathrm{M}$ and $6 \mu \mathrm{M} \beta$ lapachone for $6 \mathrm{~h}$. After a $24 \mathrm{~h}$ incubation in a normal medium, the cells were sampled, stained with Wright dye, and examined under light microscopy. Magnification, x 200. (B) The untreated control cells and $\beta$-lapachone-treated cells with $\beta$-lapachone for $6 \mathrm{~h}$ were harvested after a further $24 \mathrm{~h}$ culture, spun down, and stained with a DAPI solution $(1 \mu \mathrm{g} / \mathrm{ml})$. After a 10 min incubation at room temperature, the cells were washed with PBS and photographed with a fluorescence microscope using a blue filter. Magnification, $\mathrm{x}$ 400. (C) Total cell lysates from the untreated control and the cells that were treated with $\beta$-lapachone were prepared and subjected to 8\% SDS-polyacrylamide gel electrophoresis and transferred onto a nitrocellulose membrane. Western blot was detected with an antibody against PARP and ECL detection.

variable in size, with protuberances that resulted in more of a spindle shape, membrane shrinking, and cell rounding up (Fig. 2A). Moreover, the percentage of apoptotic sub-G1 cells increased in a time-dependent manner (Fig. 1B). Therefore, we investigated whether $\beta$-lapachone could induce apoptosis in PC-3 cells using DAPI staining and PARP cleavage. The control cells displayed an intact nuclear structure, while cells that were treated with $\beta$-lapachone had chromosomal condensation and formation of apoptotic bodies, which indicated that $\beta$-lapachone induced apoptotic cell death (Fig. 2B). A Western blot analysis showed that the $\beta$-lapachone treatment induced the degradation of the PARP protein and accumulation of the $85 \mathrm{kDa}$ in $\beta$-lapachone-treated cells (Fig. $2 \mathrm{C})$. These results, therefore, indicate that the growth 
(A)

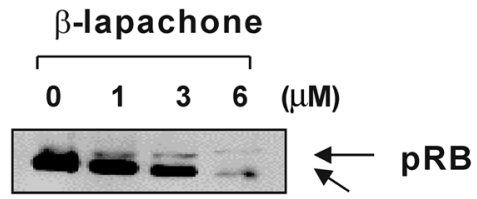

(B)

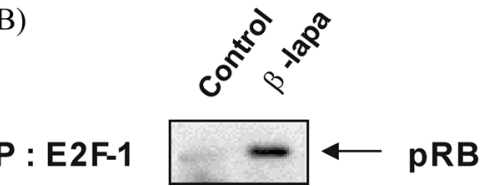

Fig. 3. Hypophosphorylation of $p R B$ and enhanced association of $\mathrm{pRB}$ and $\mathrm{E} 2 \mathrm{~F}-1$ in PC-3 cells after exposure to $\beta$-lapachone. The untreated control cells and $\beta$-lapachone-treated cells with $\beta$ lapachone for $6 \mathrm{~h}$ were harvested after a further $24 \mathrm{~h}$ culture. (A) Total cell lysates were prepared and separated by $8 \%$ SDSpolyacrylamide gel. Western blotting was performed using antipRB and ECL detection. (B) Whole cell lysates $(0.5 \mathrm{mg}$ of protein) from the control cells and the cells that were treated with $\beta$-lapachone were immunoprecipitated with an anti-E2F-1 antibody. Immuno-complexes were separated by $8 \%$ SDSpolyacrylamide gel electrophoresis, transferred to a nitrocellulose membrane, and probed with an anti-pRB antibody. Proteins were detected by ECL detection.

inhibition that was observed in response to $\beta$-lapachone is due to either a growth arrest of the cells or apoptotic cell death.

Down-regulation of pRB phosphorylation and increased binding of $\mathbf{p R B}$ and E2F-1 by $\boldsymbol{\beta}$-lapachone Since $\beta$ lapachone arrests cells in the G1 phase (as assessed by DNA flow cytometry), then the $R B$ gene product $\mathrm{pRB}$ is an important checkpoint protein in the G1 phase of the cell cycle. We next determined the kinetics between the phosphorylation of $\mathrm{pRB}$ and the transcription factor E2F-1. The total levels of the pRB expression decreased remarkably, and changed from the hyperphosphorylated form to the hypophosphorylated form by the $\beta$-lapachone treatment (Fig. 3A). The association of $\mathrm{pRB}$ and E2F-1 was almost undetectable by a co- immunoprecipitation analysis of the untreated log phase cells. However, there was a strong increase in the association of $\mathrm{pRB}$ and E2F-1 in the $\beta$-lapachone-treated cells (Fig. 3B), which suggests that $\beta$-lapachone inhibits the releasing of the E2F-1 protein from $\mathrm{pRB}$.

$\beta$-Lapachone down-regulates Cdks and cyclin Edependent kinase activity We next tested whether $\beta$ lapachone altered the expression levels of the G1 regulatory proteins. As demonstrated in Fig. 4A, it did not affect the protein levels of $\mathrm{Cdk} 2, \mathrm{Cdk} 4$, and cyclin E. However, as shown in Figure 4B, the kinase activity of these proteins was significantly inhibited in response to $\beta$-lapachone in a concentration-dependent manner. These results suggest that the suppressive effect of $\beta$-lapachone on the cell growth of the PC-3 cells was partly caused by down-regulating the activity of Cdks and the cyclin E-associated kinase without altering the expression of their proteins.

$\beta$-Lapachone induces the Cdk inhibitor p21 protein and enhanced association of $\mathbf{p 2 1}$ with $\mathbf{C d k} 2$ To understand the molecular mechanism by which $\beta$-lapachone down-regulates Cdks and the cyclin E-dependent kinase activity, we investigated whether the Cdk inhibitors were involved in the $\beta$-lapachone-induced growth arrest in PC-3 cells. In the untreated control cells, the expression of the p21 protein was undetectable. However, incubation of the cells with $\beta$ lapachone caused a striking dose- and time-dependent increase that was blocked by actinomycin D (Fig. 5A, B and $\mathrm{C}$ ); whereas, $\beta$-lapachone did not affect the expression of other Cdk inhibitors, including p27 and p16 (data not shown). In addition, the association of $\mathrm{p} 21$ with $\mathrm{Cdk} 2$ was not detected in the untreated control cells. However, treatment of the cells with $\beta$-lapachone resulted in a significant increase in the binding of p21 and Cdk2 (Fig. 5D), which suggests that the down-regulation of the Cdks kinase activity by $\beta$-lapachone is mainly caused by the interaction between $\mathrm{Cdk} 2$ and the highly-induced p21.
(A)

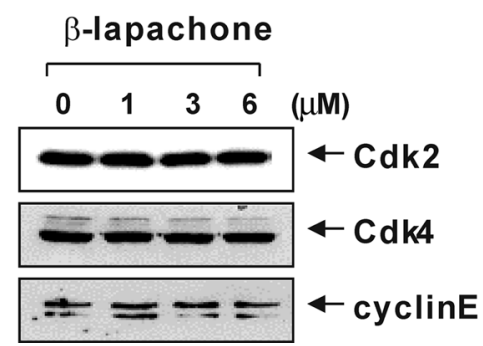

(B)

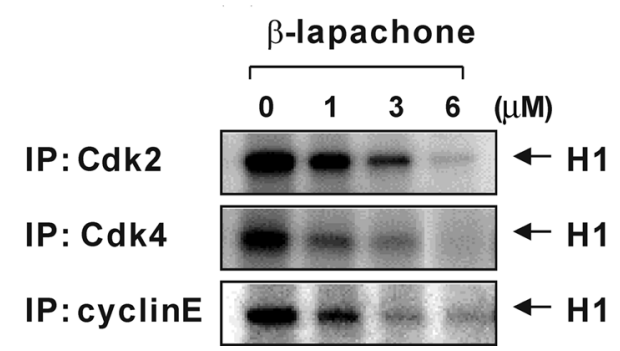

Fig. 4. Effects of $\beta$-lapachone on the protein levels of Cdk2, Cdk4, and cyclin E, and their kinase activities in PC-3 cells. (A) Total cell lysates were prepared and subjected to $10 \%$ SDS-polyacrylamide gels, and transferred to nitrocellulose membranes. Western blots were detected with the indicated antibodies, and ECL detection. (B) Total cell lysates ( $0.5 \mathrm{mg}$ protein) from the control cells and the cells that were treated with $\beta$-lapachone were immunoprecipitated with anti-Cdk2, anti-Cdk4, or anti-cyclin E antibody. Kinase activity was assayed using histone $\mathrm{H} 1$ as substrates. Phosphorylated histone H1 (H1) was analyzed by a 10\% SDS-polyacrylamide gel electrophoresis and autoradiography. 
(A)

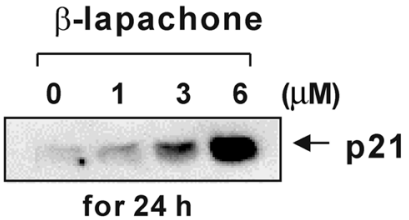

(C)

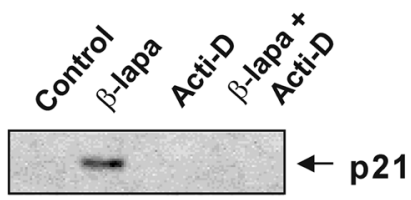

(B)

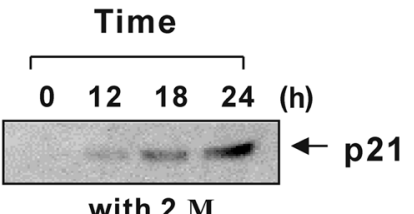

(D)

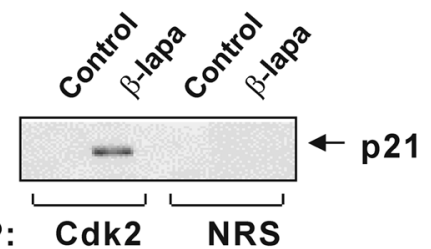

Fig. 5. Induction of Cdk inhibitor p21, and enhanced association of p21 with Cdk2 in PC-3 cells after exposure to $\beta$-lapachone. (A and B) The cells were treated with $\beta$-lapachone at $1 \mu \mathrm{M}, 3 \mu \mathrm{M}$, and $6 \mu \mathrm{M}$ concentrations for $6 \mathrm{~h}$, then further cultured in a normal medium for $24 \mathrm{~h}$, or the cells were treated with $2 \mu \mathrm{M} \beta$-lapachone for the indicated time. (C) The cells were incubated with $2 \mu \mathrm{M} \beta$-lapachone ( $\beta$-lapa), $100 \mu \mathrm{g} / \mu \mathrm{l}$ actinomycin D (Acti-D), or $\beta$-lapachone plus actinomycin D for $24 \mathrm{~h}$. (D) The cells were treated with $2 \mu \mathrm{M} \beta$ lapachone for $24 \mathrm{~h}$. The cell lysates were immunoprecipitated with an anti-Cdk2 antibody or normal rabbit serum (NRS), and immunoprecipitates were collected. Equal amounts of whole proteins or immunoprecipitated proteins were separated by $12 \%$ SDSpolyacrylamide gels, transferred to nitrocellulose membranes, and probed with an anti-p21 antibody. The proteins were detected by ECL detection.
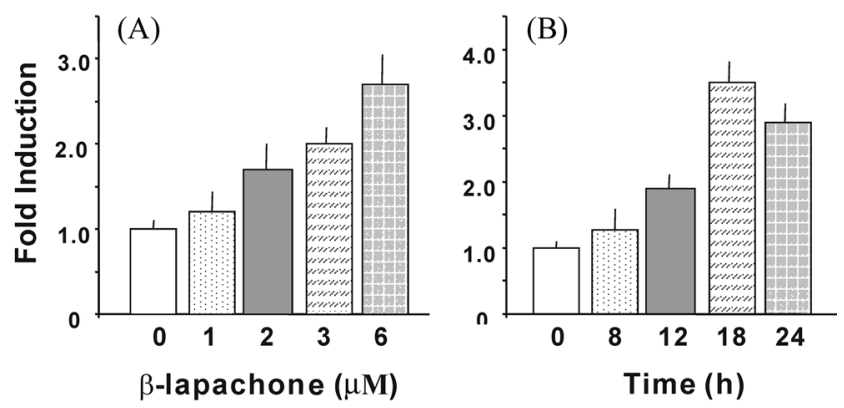

Fig. 6. Activation of $\mathrm{p} 21$ promoter-luciferase fusion plasmids in PC-3 cells after exposure to $\beta$-lapachone. The p21 promoter construct fused to the luciferase gene, and the $\beta$-galactosidase reporter vectors were transiently co-transfected into cells. The cells were treated with different concentrations of $\beta$-lapachone for $6 \mathrm{~h}$ and further cultured in a normal medium for $24 \mathrm{~h}(\mathrm{~A})$, or the cells were treated with $2 \mu \mathrm{M} \beta$-lapachone for the indicated time (B). Luciferase activities, which were normalized to the $\beta$ galactosidase enzyme assay system, were expressed as fold increase from the control. The results are expressed as the mean $\pm \mathrm{SD}$ of data from two separate experiments.

$\boldsymbol{\beta}$-Lapachone induces the activation of the p21 promoter Since the p21 expression is markedly induced by $\beta$-lapachone, we subsequently investigated if the up-regulation of the p21 expression involves the transcriptional regulation of the $\mathrm{p} 21$ gene promoter. As shown in Fig. 6, following exposure to $\beta$ lapachone, the p21 promoter construct was significantly activated in a concentration- and time-dependent manner up to a $18 \mathrm{~h}$ exposure. As the p53 gene is deleted in PC-3 cells (Kozlowski et al., 1984; Rubin et al., 1991), our data indicated that $\beta$-lapachone arrests the cell cycle at the G1 phase, in part through the induction of $\mathrm{p} 21$ in a p53-independent manner.

\section{Discussion}

We tested $\beta$-lapachone for its activity in inhibiting the growth of human prostate carcinoma PC-3 cells. We found that treatment of the cells with $\beta$-lapachone resulted in a concentration-dependent inhibition of cell viability (Fig. 1A), which was associated with gross morphological changes. Subsequent experiments addressed the issue of whether this compound agitates the cell cycle (using a DNA flow cytometric analysis) and induces apoptosis (using Western blotting for PARP cleavage and DAPI staining). Flow cytometric data of the $\beta$-lapachone-treated cells clearly revealed a cell-cycle block at the $\mathrm{G} 1$ to $\mathrm{S}$ phase transition and an accumulation of cells at the sub-G1 apoptotic region (Fig. 1B), which contained less DNA than the G1 cells (Evans, 1993; Loo and Rillema, 1998). Furthermore, chromatin condensation and proteolytic cleavage of PARP were observed after the treatment of $\beta$-lapachone (Fig. 2B and C), which indicates the occurrence of apoptotic cell death (Evans, 1993; Loo and Rillema, 1998; Scovassi et al., 1998). These results suggest that $\beta$-lapachone interferes with proliferation and induces apoptosis in close association with the G1 arrest by modulation of cell cycle-regulatory proteins and associated kinase activities as a possible molecular mechanism of the effect of $\beta$-lapachone. Therefore, we investigated the effects of $\beta$-lapachone on the expression of G1/S transition regulatory proteins to analyze the mechanism of the G1 arrest. As shown in Fig. 3A, we found that there was a loss of phosphorylated pRB protein by treatment with $\beta$-lapachone and a marked binding of $\mathrm{pRB}$ and $\mathrm{E} 2 \mathrm{~F}-1$ in response to the $\beta$-lapachone treatment (Fig. 3B). This indicates that $\beta$-lapachone indirectly inhibited the transcriptional activity of the E2F family for the S phase entry (DeGregori et al., 1995; Weinberg, 1995; Sidle 
et al., 1996). The results from the in vitro kinase assay demonstrated that $\beta$-lapachone inhibits Cdks and the cyclin Edependent activity, rather than altering these protein levels (Fig. 4), which plays an essential role in cell cycle progression at the G1 to S phase transition stage (Matsushime et al., 1992; Koff et al., 1992). These results were consistent with the effective concentration and time that could significantly induce the growth inhibition, cell cycle arrest, and apoptosis. Furthermore, we assumed that the down-regulation of Cdks and cyclin E-dependent kinase activity as well as the cell cycle arrest by $\beta$-lapachone may be also involved by an additional inhibitory mechanism (s). To elucidate this hypothesis, we next investigated whether Cdk inhibitors (such as p21, p27, and p16) are involved in the $\beta$-lapachone-induced growth arrest using Western blotting and co-immunoprecipitation analysis. This hypothesis was clearly supported by the following facts: (1) $\beta$-lapachone selectively induced the expression of the Cdk inhibitor p21 protein, which was blocked by the transcription inhibitor actinomycin D. (2) The increased p21 proteins by the $\beta$-lapachone treatment were tightly associated with Cdk2. (3) $\beta$-lapachone activated the p21 promoter-luciferase fusion plasmids (Fig. 6). These results demonstrate that the down-regulations of $\mathrm{Cdks}$ and the cyclin E-dependent kinase activity are mainly caused by selective induction of the p21 expression, and further indicate that $\beta$-lapachone regulates the transcriptional level of the $\mathrm{p} 21$ expression. Even though p21 was first identified as a tumor suppressor p53-inducible gene, it has also been shown to mediate the induction of cell cycle arrest at the G1 phase after DNA damage (El-Deiry et al., 1993; Xiong et al., 1993; Waldman et al., 1995). Also, p21 can be induced in a p53independent mechanism in various cell lines that are stimulated for growth arrest, differentiation, and apoptosis (Datto et al., 1995; Zeng and El-Deiry, 1996; Vogt et al., 1997; Choi et al., 2000). Because the p53 gene is truncated and the p53 protein is absent in PC-3 cells (Kozlowski et al., 1984; Rubin et al., 1991) that were used in this study, the present data clearly demonstrate that $\beta$-lapachone is regulating the level of the p21 expression through a p53-independent pathway.

In summary, we have addressed that $\beta$-lapachone strongly inhibits cell proliferation and induces apoptosis in the human prostate carcinoma PC-3 cells. These results provide convincing evidence that $\beta$-lapachone exerts its effect on cell cycle progression of PC-3 cells by two pathways. First, by a significant decrease in the phosphorylated forms of tumor suppressor pRB that lead to its inhibitory effect of the E2Fdependent transcriptional activity of the genes that control the transition from the $\mathrm{G} 1$ to $\mathrm{S}$ phase and subsequent DNA synthesis. Second, by an increase in the p21 expression that leads to its increased binding with cyclin/Cdk complexes, which results in a marked decrease in their kinase activities. When these results are compared with those that were obtained for the growth study and cell cycle phase distribution following the $\beta$-lapachone treatment of PC-3-M cells, it can be suggested that the p53-independent regulation of $\mathrm{p} 21$ could be the major cause of the effect of $\beta$-lapachone on the G1 arrest and anti-proliferative response.

Acknowledgments We thank J. Trepel (National Institutes of Health, USA) for her thoughtful assistance, and Dr. D. Boothman (Case Western Reserve University, USA) for providing $\beta$-lapachone in the initial phase of this study. This work was partly supported by grant No. 2001-1-20700-005-3 from the Basic Research Program of the Korea Science \& Engineering Foundation.

\section{References}

Boorstein, R. J. and Pardee, A. B. (1984) $\beta$-lapachone greatly enhances MMS lethality to human fibroblasts. Biochem. Biophys. Res. Commun. 118, 828-834.

Boothman, D. A., Trask, D. K. and Pardee, A. B. (1989) Inhibition of potentially lethal DNA damage repair in human tumor cells by $\beta$-lapachone, an activator of topoisomerase I. Cancer Res. 49, 605-612.

Choi, Y. H., Lee, S. J., Nguyen, P., Jang, J. S., Lee, J., Wu, M. L., Takano, E., Maki, M., Henkart, P. A. and Trepel, J. B. (1997) Regulation of cyclin D1 by calpain protease. J. Biol. Chem. 272, 28479-28484.

Choi, Y. H., Lee, W. H., Park, K. Y. and Zhang, L. (2000) p53independent induction of $\mathrm{p} 21$ (WAF1/CIP1), reduction of cyclin B1 and $\mathrm{G} 2 / \mathrm{M}$ arrest by the isoflavone genistein in human prostate carcinoma cells. Jpn. J .Cancer. Res. 91, 164-173.

Cruz, F. S., Docampo, R. and Boveris, A. (1978) Generation of superoxide anions and hydrogen peroxide from $\beta$-lapachone in bacteria. Antimicrob. Agents Chemother. 14, 630-633.

Datto, M. B., Yu, Y. and Wang, X. F. (1995) Functional analysis of the transforming growth factor $\beta$ responsive elements in the WAF/Cip1/p21 promoter. J. Biol. Chem. 270, 28623-28628.

DeGregori, J., Leone, G., Ohtani, K., Miron, A. and Nevins, J. R. (1995) E2F-1 accumulation bypasses a G1 arrest resulting from the inhibition of G1 cyclin-dependent kinase activity. Genes Dev. 9, 2873-2887.

Docampo, R., Cruz, F. S., Boveris, A., Muniz, R. P. and Esquivel, D. M. (1979) $\beta$-Lapachone enhancement of lipid peroxidation and superoxide anion and hydrogen peroxide formation by sarcoma 180 ascites tumor cells. Biochem. Pharmacol. 28, 723728.

El-Deiry, W. S., Tokino, T., Velculesco, V. E., Levy, D. B., Parsons, R., Trent, J. M., Lin, D., Mercer, E. W., Kinzler, K. W. and Vogelstain, B. (1993) WAF1, a potential mediator of p53 suppression. Cell 75, 817-825.

Evans, V. G. (1993) Multiple pathways to apoptosis. Cell Biol. Int. 17, 461-476.

Frydman, B., Marton, L. J., Sun, J. S., Neder, K., Witiak, D. T., Liu, A. A., Wang, H. M., Mao, Y., Wu, H. Y., Sanders, M. M. and Liu, L. F. (1997) Induction of DNA topoisomerase IImediated DNA cleavage by $\beta$-lapachone and related naphthoquinones. Cancer Res. 57, 620-627.

Goijman, S. G. and Stoppani, A. O. (1985) Effects of $\beta$ lapachone, a peroxide-generating quinone, on macromolecule synthesis and degradation in Trypanosoma cruzi. Arch. 
Biochem. Biophys. 240, 273-280.

Guiraud, P., Steiman, R., Campos-Takaki, G. M., Seigle-Murandi, F. and Simeon de Buochberg, M. (1994) Comparison of antibacterial and antifungal activities of lapachol and $\beta$ lapachone. Planta Med. 60, 373-374.

Kim, M.-J., Jung, J., Choi, E. C., Park, H.-Y. and Lee, K. (2001) Identification of the interaction between rat translationally controlled tumor protein/IgE-dependent histamine releasing factor and myosin light chain. J. Biochem. Mol. Biol. 34, 526530.

Koff, A., Giordano, A., Desai, D., Yamashita, K., Harper, J. W., Elledge, S., Nishimoto, T., Morgan, D. O., Franza, B. R. and Roberts, J. M. (1992) Formation and activation of a cyclin Ecdk2 complex during the G1 phase of the human cell cycle. Science 272, 1689-1694.

Kozlowski, J. M., Isaiah, J. F., Campbell, D., Xu, Z. L., Kaighn, M. E. and Hart, I. R. (1984) Metastatic behavior of human tumor cell lines grown in the nude mouse. Cancer Res. 44, 3522-3529.

Li, C. J., Averboukh, L. and Pardee, A. B. (1993) $\beta$-Lapachone, a novel DNA topoisomerase I inhibitor with a mode of action different from camptothecin. J. Biol. Chem. 268, 22463-22468.

Li, C. J., Wang, C. and Pardee, A. B. (1995) Induction of apoptosis by $\beta$-lapachone in human prostate cancer cells. Cancer Res. 55, 3712-3715.

Li, Y., Li, C. J., Yu, D. and Pardee A.B. (2000) Potent induction of apoptosis by beta-lapachone in human multiple myeloma cell lines and patient cells. Mol. Med. 6, 1008-1015.

Loo, D. T. and Rillema, J. R. (1998) Measurement of cell death. Methods Cell Biol. 57, 251-264.

Lopes, J. N., Cruz, F. S., Docampo, R., Vasconcellos, M. E., Sampaio, M. C., Pinto, A. V. and Gilbert, B. (1978) In vitro and in vivo evaluation of the toxicity of 1,4-naphthoquinone and 1,2-naphthoquinone derivatives against Trypanosoma cruzi. Ann. Trop. Med. Parasitol. 72, 523-531.

Manna, S. K., Gad, Y. P., Mukhopadhyay, A. and Aggarwal, B. B. (1999) Suppression of tumor necrosis factor-activated nuclear transcription factor- $\mathrm{\kappa B}$, activator protein-1, c-Jun N-terminal kinase, and apoptosis by $\beta$-lapachone. Biochem. Pharmacol. 57, 763-774.

Matsushime, H., Ewen, M. E., Strom, D. K., Kato, J. Y., Hanks, S. K., Roussel, M. F. and Sherr, C. J. (1992) Identification and properties of an atypical catalytic subunit (p34PSK-J3/cdk4) for mammalian D type G1 cyclins. Cell 71, 323-334.

Pardee, A. B., Li, Y. Z. and Li, C. J. (2002) Cancer therapy with beta-lapachone. Curr. Cancer Drug Targets 2, 227-242.

Planchon, S. M., Wuerzberger, S., Frydman, B., Witiak, D. T.,
Hutson, P., Church, D. R., Wilding, G. and Boothman, D. A. (1995) $\beta$-lapachone-mediated apoptosis in human promyelocytic leukemia (HL-60) and human prostate cancer cells: a p53-independent response. Cancer Res. 55, 3706-3711.

Rubin, S. J., Hallahan, D. E., Ashman, C. R., Brachman, D. G., Beckett, M. A., Virudachalam, S., Yandell, D. W. and Weichselbaum, R. R. (1991) Two prostate carcinoma cell lines demonstrate abnormalities in tumor suppressor genes. J. Surg. Oncol. 46, 31-36.

Schaffner-Sabba, K., Schmidt-Ruppin, K. H., Wehrli, W., Schuerch, A. R. and Wasley, J. W. (1984) B-Lapachone: synthesis of derivatives and activities in tumor models. J. Med. Chem. 27, 990-994.

Scovassi, A. I., Denegri, M., Donzelli, M., Rossi, L., Bernardi, R., Mandarino, A., Frouin, I. and Negri, C. (1998) Poly(ADPribose) synthesis in cells undergoing apoptosis: an attempt to face death before PARP degradation. Eur. J. Histochem. 42, 251-258.

Shim, M. J., Kim, H. J., Yang, S. J., Lee, I. S., Choi, H. I. and Kim, T. (2002) Arsenic trioxide induces apoptosis in chronic myelogenous leukemia K562 cells: possible involvement of p38 MAP kinase. J. Biochem. Mol. Biol. 35, 377-383.

Sidle, A., Palaty, C., Dirks, P., Wiggan, O., Kiess, M., Gill, R. M., Wong, A. K. and Hamel, P. A. (1996) Activity of the retinoblastoma family proteins, pRB, p107, and p130, during cellular proliferation and differentiation. Crit. Rev. Biochem. Mol. Biol. 31, 237-271.

Vanni, A., Fiore, M., De Salvia, R., Cundari, E., Ricordy, R., Ceccarelli, R. and Degrassi, F. (1998) DNA damage and cytotoxicity induced by $\beta$-lapachone: relation to poly(ADPribose) polymerase inhibition. Mutat. Res. 401, 55-63.

Vogt, A., Sun, J., Qian, Y., Hamilton, A. D. and Sebti, S. M. (1997) The geranylgeranyltransferase-I inhibitor GGTI-298 arrests human tumor cells in G0/G1 and induces p21(WAF1/ CIP1/SDI1) in a p53-independent manner. J. Biol. Chem. 272, 27224-27229.

Waldman, T., Kinzler, K. W. and Vogelstain, B. (1995) p21 is necessary for the p53-mediated G1 arrest in human cancer cells. Cancer Res. 55, 5187-5190.

Weinberg, R. A. (1995) The retinoblastoma protein and cell cycle control. Cell 81, 323-330.

Xiong, Y., Hannon, G., Zhang, H., Casso, D., Kobayashi, R. and Beach, D. (1993) p21 is a universal inhibitor of cyclin kinases. Nature 366, 701-704.

Zeng, Y. X. and El-Deiry, W. S. (1996) Regulation of p21 WAFl/CIPI expression by p53-independent pathways. Oncogene 12, 15571564. 